\title{
Elementary and Secondary School Teachers' Needs for Media Education: With Focus on Curriculum Development for Professional Development
}

\author{
Hiroki Yoshida
}

\begin{abstract}
The purpose of the study is to identify elementary and secondary school teachers' needs for media education training courses. A questionnaire survey was conducted from October to November, 2013. The participants were 49 elementary and secondary school teachers. A four point Likert scale questionnaire was used to measure teachers' needs for the current "curriculum standards" and a free-response style self-report questionnaire was used to identify participants' needs for new media education in-service teacher training courses. Participants were asked what they want to study in an in-service teacher training course for media education. Participants' answers were classified using quantification method type III. Results of the research reveal that media education training courses with high needs were: utilizing digital textbooks, utilizing tablet PCs, utilizing interactive blackboards/ whiteboards, ICT integration in education, capacity building for ICT integration, designing ICT integrated lessons, utilizing ICT in specific subjects, and moral issues in education.
\end{abstract}

Index Terms-Needs assessment, professional development, teacher training, media education, capacity building.

\section{INTRODUCTION}

In order to cope with the highly-sophisticated information society, the Strategic Headquarters for the Promotion of an Advanced Information and Telecommunications Network Society (hereinafter referred to as Strategic Headquarters) announced "A New Strategy in Information and Communications Technology (IT)" on May 11th, 2010 and required the nation to develop a school system for the 21 st century. The Strategic Headquarters recommended schools to utilize ICT to "(i) develop easy-to-understand classroom environment where children teach and learn from one another; (ii) reduce burden on the teachers and staff; and (iii) expand children's capability to utilize information," and required the Japanese Ministry of Education, Culture, Sports, Science and Technology (hereinafter abbreviated to MEXT) to establish a basic policy for the informatization of education [1].

Responding to the Strategic Headquarters' request, the MEXT announced "The Vision for ICT in Education" on April 28, 2011. The Vision focuses to take full advantage of the features of ICT in order to provide education to foster

Manuscript received May 18, 2014; revised July 20, 2014. This work was supported by JSPS KAKENHI Grant Number 25350360, and the grant from the Japan Association of Lifelong Education.

Hiroki Yoshida is with Tokoha University, Shizuoka, Japan (e-mail: h-yoshida@sz.tokoha-u.ac.jp). abilities required for children who will lead the 21st century [2]. To meet the goal of the Vision, the Japanese Government aims to make all teachers ICT literate. However, the results of the "Countrywide Survey on the Situations of Informatization of Japanese Schools" announced by MEXT in July, 2011 shows that only 76.1 percent of the teachers can use ICT for class preparation, class evaluation and educational research, 61.5 percent can utilize ICT in classroom lessons, 62.3 percent can foster students' ICT literacy, 71.4 percent can cope with and teach moral issues in ICT, and 72.4 percent can utilize ICT for school affairs [3].

The Strategic Headquarters then announced a "Declaration to be the World's Most Advanced IT Nation" which was decided by the Cabinet on June 14th, 2013. The strategy is intended to "create an IT user society at the world's highest levels and disseminate the results globally through a five-year process (by 2020)" [4]. The Strategic Headquarters required elementary and secondary schools to equip high-speed broadband, wireless LAN, one computer per student, interactive blackboards/whiteboards, digital textbooks and other educational materials to get students in touch with ICT. In concurrence with equipping schools with ICT, the Strategic Headquarters also required MEXT to develop teachers' capacity to integrate ICT in education, and develop ICT integrated teaching and learning models in order to take full advantage of the ICT equipped educational environments.

Capacity building and professional development along with infrastructure building and installation of educational media are crucial factors of the quality of education. Therefore, efforts have been made to develop an effective and well-structured media education teacher training curriculum standards, to promote in-service and pre-service teacher training at the local and national level, and to motive teachers to take the training programs and/or courses. One of the efforts made by the MEXT to enhance teachers' knowledge and skills in media education is the development of the "Educational Media Teacher Training Curriculum Standards" (hereinafter abbreviated as "curriculum standards") which was first developed in 1973 [5]. The "curriculum standards" has been introducing knowledge and skills required for teachers and educational staffs, and has been a reference material for regional curriculum planners in planning and organizing regional training courses.

The "curriculum standards" had been revised twice so far. The first revision of the "curriculum standards" was made by the MEXT in March, 1992 [6]. The revised "curriculum standards" incorporated new technologies such as computers, telecommunication systems and databases, introducing 93 
training courses.

The second and last revision of the "curriculum standards" was made in March 2006, and was announced by MEXT on November 24th, 2006 [7]. The new and current "curriculum standards" involves four categories: training courses, training topics, training sub-topics, and training contents. The current "curriculum standards" consists of 22 training courses with 74 training topics, 317 sub-topics and 1,065 training contents The reason why more than 300 sub-topics and 1,000 training contents were established was to enable constant revision of the "curriculum standards" so as to deal with the rapid development of educational media, and to expand the range of options for regional training curriculum planners.

However, since eight years have passed since the current "curriculum standards" was published in 2006, and since the situation of media education has radically changed, it is necessary to identify school teachers' needs for the current "curriculum standard" and their needs for new media education teacher training courses. Previous study suggests the necessity to find out teachers' needs for professional development in media education.

According to the results of a formative evaluation of the current "curriculum standards" which was conducted in November 2009, 25 out of 33 teacher consultants and social education consultants who designed media education teacher training courses using the new "curriculum standards" commented that part of the "curriculum standards" should be revised, while only 6 teachers and social education consultants said that the "curriculum standards" does not have to be revised [8]. Furthermore, a questionnaire survey conducted in November 2011 revealed that teacher consultants and social education consultants recognize that they have to train or teach teachers in their regions moral issues in education, how to utilize smartphones for education, how to utilize interactive blackboards for education, how to utilize tablet PCs for education, how to utilize mobile learning devices (e.g. Nintendo DS, PSP) for education, and how to design ICT integrated lessons [9]. The participants in these two studies were teacher consultants and social education consultants who serve as regional curriculum planners/ developers in each prefecture or region. So it is necessary to investigate school teachers' needs for media education -who participate in regional training courses as trainees - in order to develop a useful "curriculum standards" with valid contents in the context of in-service teacher professional development.

Therefore, this study aims to identify elementary and secondary school teachers' needs for in-service teacher training courses related with media education.

\section{PURPOSE}

The purpose of the study is to identify elementary and secondary school teachers' needs for training courses related with media education.

The research questions to be addressed in this paper are: 1) What are elementary and secondary school teachers' needs for the current "curriculum standards?" 2) What do elementary and secondary school teachers want to learn in media education in-service teacher training courses? 3) What is the structure of teachers' needs for media education training courses?

\section{Methodology}

A questionnaire survey was conducted from October to November 2013 with the purpose of identifying elementary and secondary school teachers' needs for training courses for media education, and the structure of the teachers' needs for the training courses.

\section{A. Participants}

The questionnaire was mailed to 93 elementary and secondary school teachers working in educational institutes. A total of 49 valid replies were obtained for the questionnaire. The collection rate was $52.69 \%$.

\section{B. Questionnaire}

A four point Likert scale questionnaire was used to measure teachers' needs for the current "curriculum standards" and a free-response style self-report questionnaire was used to identify the participants' needs for new media education teacher training courses.

\section{REsUlTS}

All of the participants who replied to the questionnaire completed it. This means that the response rate was 100.00 percent. Hereinafter, the results of the 49 answers will be introduced.

\section{A. Teachers' Needs for the Current "Curriculum Standards",}

Participants completed a questionnaire that assesses their needs for the current "curriculum standards." The questionnaire consists of 74 questions that that refer to the training topics introduced in the "curriculum standards." The participants were asked if they want to participate in a training course or program based on the 74 training topics of the "curriculum standards." Questions were based on a 4-point Likert scale ranging from 1 (strongly disagree) to 4 (strongly agree).

Table I shows the participants' needs for the current "curriculum standards." The mean was calculated by giving each of the Likert scale points a number value, where strongly disagree $=1$, disagree $=2$, agree $=3$, and strongly agree $=4$.

Results of the needs analysis show that training topics of the "curriculum standards" with high needs $(>3.50)$ were: utilizing educational media, media literacy, utilizing media in education, utilizing presentation software in education, operating presentation software, utilizing hypermedia/ multimedia in education, utilizing the Internet in education, operating the Internet, utilizing websites in education, utilizing educational software, moral issues and netiquette, copyright issues, protection of personal information, network security, rating and filtering information, protection from hazardous and harmful websites, and managing and operating media in schools.

On the other hand, training topics with relatively low needs $(<2.00)$ were: utilizing $16 \mathrm{~mm}$ movie projectors, 
utilizing slide projectors, utilizing overhead projectors, and producing and utilizing still images.

TABLE I: TEACHERS' NEEDS FOR THE CURRENT “CURRICULUM STANDARDS"

\begin{tabular}{|c|c|}
\hline Training Topics & Mean \\
\hline 1. Trends and Issues of Educational Media & 3.41 \\
\hline 2. Utilizing Educational Media & 3.58 \\
\hline 3. Managing and Operating Educational Media & 3.32 \\
\hline 4. Media Literacy & 3.73 \\
\hline 5. Utilizing Media in Education & 3.62 \\
\hline 6. Utilizing Educational Broadcasting & 3.25 \\
\hline 7. Trends in Educational Broadcasting & 3.08 \\
\hline 8. Video and TV Program Production & 2.64 \\
\hline 9. Utilizing School PA Systems & 3.00 \\
\hline 10. Installing and Operating School PA Systems & 2.89 \\
\hline 11. Utilizing $16 \mathrm{~mm}$ Movie Projectors & 2.00 \\
\hline 12. Utilizing Slide Projectors & 1.61 \\
\hline 13. Utilizing Overhead Projectors & 1.57 \\
\hline 14. Utilizing Visual Presenters and Overhead Cameras & 2.97 \\
\hline 15. Utilizing DVD/HDD Recorders & 2.84 \\
\hline 16. Utilizing Large-screen LCD TVs and/or PDP TVs & 3.42 \\
\hline 17. Producing Slides and Projection Materials & 2.35 \\
\hline 18. Utilizing Slides and Projection Materials & 2.77 \\
\hline 19. Producing and Utilizing Still Images & 1.64 \\
\hline 20. Producing Video Materials & 2.81 \\
\hline 21. Operating Digital Cameras & 3.03 \\
\hline 22. Utilizing Printers & 2.83 \\
\hline 23. Producing Sound Recording Materials & 2.44 \\
\hline 24. Producing Video Recording Materials & 2.81 \\
\hline 25. Producing and Utilizing DVDs and CDs & 2.87 \\
\hline 26. Utilizing Sound Recording Materials & 2.58 \\
\hline 27. Utilizing Video Recording Materials & 2.95 \\
\hline 28. Utilizing VOD Systems & 3.00 \\
\hline 29. Overview of Computer Aided Education & 3.25 \\
\hline 30. Computer Hardware & 2.73 \\
\hline 31. Computer Software & 2.95 \\
\hline 32. Basic Computer Skills & 3.03 \\
\hline 33. Utilizing Word-processing Software in Education & 3.08 \\
\hline 34. Operating Word-processing Software & 3.17 \\
\hline 35. Utilizing Spreadsheet Software in Education & 3.22 \\
\hline 36. Operating Spreadsheet Software & 3.32 \\
\hline 37. Utilizing Presentation Software in Education & 3.67 \\
\hline 38. Operating Presentation Software & 3.63 \\
\hline 39. Utilizing Database Software in Education & 3.11 \\
\hline 40. Operating Database Software & 3.08 \\
\hline 41. Utilizing Hypermedia/Multimedia in Education & 3.50 \\
\hline 42. Developing Hypermedia/Multimedia & 3.08 \\
\hline 43. Utilizing Computer Networks in Education & 3.22 \\
\hline 44. Operating Computer Networks & 3.08 \\
\hline 45. Managing Computer Networks & 3.14 \\
\hline 46. Utilizing the Internet in Education & 3.61 \\
\hline 47. Operating the Internet & 3.50 \\
\hline 48. Operating Communication Tools & 3.43 \\
\hline 49. Utilizing E-mail in Education & 3.28 \\
\hline 50. Operating E-mail Programs & 3.31 \\
\hline 51. Utilizing Websites in Education & 3.66 \\
\hline 52. Operating Websites & 3.39 \\
\hline
\end{tabular}

\begin{tabular}{l|l}
\hline 53. Utilizing Educational Software & 3.50 \\
\hline 54. Utilizing Groupware in Education & 3.33 \\
\hline 55. Moral Issues and Netiquette & 3.97 \\
\hline 56. Copyright Issues & 3.89 \\
\hline 57. Protection of Personal Information & 3.87 \\
\hline 58. Network Security & 3.84 \\
\hline 59. Rating and Filtering Information & 3.84 \\
\hline 60. Protection from Hazardous and Harmful Websites & 3.76 \\
\hline 61. Utilizing Videoconference & 2.86 \\
\hline 62. Utilizing E-Learning (WBL) & 2.89 \\
\hline 63. Utilizing the el-Net & 2.34 \\
\hline 64. Utilizing Electronic Whiteboards & 2.89 \\
\hline 65. Utilizing GPSs, Navigation Systems & 2.53 \\
\hline 66. Utilizing Handheld Terminals & 3.46 \\
\hline 67. Meanings and Management of Audiovisual \\
Centers/Libraries & 3.13 \\
\hline 68. Managing and Operating Media in Schools & 3.51 \\
\hline 69. Utilizing CATV & 2.58 \\
\hline 70. The Structure of the “Educational Media Teacher Training & 2.97 \\
\hline Curriculum Standards" & 2.97 \\
\hline 71. Creating Training Manuals & 3.08 \\
\hline 72. Problems in Organizing Training Courses & 3.00 \\
\hline 73. Establishing Regional Cooperation Systems & 3.05 \\
\hline 74. Evaluating Training Courses & \\
\hline \hline
\end{tabular}

\section{B. Teachers' Needs for New Training Courses}

The KJ method was used to group the participants' needs statements with similar contents or characteristics together. As a result, 16 needs statements were determined for the needs for media education training courses (see Table II).

Results of the survey reveal that training courses with high needs were: utilizing digital textbooks, utilizing tablet PCs, utilizing interactive blackboards/whiteboards, ICT integration in education, capacity building for ICT integration, designing ICT integrated lessons, utilizing ICT in specific subjects, and moral issues in education.

Rationale for the relatively high need for being trained how to utilize digital textbooks, tablet PCs, and interactive blackboards/whiteboards in education is because the Strategic Headquarters required elementary schools and secondary schools to equip one computer per student, interactive blackboards, digital textbooks and other educational materials [4].

It is presumed that high needs for learning how to integrate ICT in education, foster capacity for ICT integration, design ICT integrated lesson, and utilize ICT in specific subjects comes from the Strategic Headquarters request for developing teachers' capacity to integrate ICT in education, and develop ICT integrated teaching and learning models in order to take full advantage of the ICT equipped educational environments [4].

High needs for training courses for moral issues in education, fostering positive attitudes towards joining the information society, information security, and utilizing social networking services and issues in the information society comes from the announcement of the need for fostering information moral in the new Courses of Study for elementary schools [10] and junior high schools [11] in Japan for the first time. 
Needs for training courses related with the utilization of overhead cameras, video projectors, knowledge and skills for digital presentation, and media literacy come from the MEXT's requirement for elementary and secondary schools to equip overhead cameras and video projectors in each classroom in order to increase the effects and efficiency of classroom lessons, and to enable pupils and students to announce their ideas and findings in classroom lessons [12].

Among the 16 needs statements decided in this study, 7 statements: \#8 Moral issues in education, \#10 Utilizing overhead cameras, \#11 Information security, \#13 Issues in the information society, \#14 Digital presentation, \#15 Utilizing video projectors, \#16 Media literacy are related with the training topics introduced in the current "curriculum standards."

TABLE II: PARTICIPANTS’ NEEDS FOR NEW TRAINING COURSES

\begin{tabular}{cl|c|c}
\hline \hline Items & Frequency & $\%$ \\
\hline \hline $1 . \quad$ Utilizing digital textbooks & 26 & $53.06 \%$ \\
\hline 3. $\quad$ Utilizing tablet PCs & Utilizing interactive blackboards/ \\
\hline $4 . \quad$ ICT inteboards & 24 & $48.98 \%$ \\
\hline $5 . \quad$ Capacity building for ICT integration & 24 & $48.98 \%$ \\
\hline $6 . \quad$ Designing ICT integrated lessons & 24 & $48.98 \%$ \\
\hline $7 . \quad$ Utilizing ICT in specific subjects & 18 & $38.78 \%$ \\
\hline $8 . \quad$ Moral issues in education & 18 & $36.73 \%$ \\
\hline $9 . \quad \begin{array}{l}\text { Fostering positive attitudes towards joining } \\
\text { the information society }\end{array}$ & 13 & $26.53 \%$ \\
\hline $10 . \quad$ Utilizing overhead cameras (OHCs) & 12 & $24.49 \%$ \\
\hline $11 . \quad$ Information security & 12 & $24.49 \%$ \\
\hline 12. & Utilizing social networking services (SNSs) & 11 & $22.45 \%$ \\
\hline $13 . \quad$ Issues in the information society & 10 & $20.41 \%$ \\
\hline $14 . \quad$ Digital presentation & 9 & $18.37 \%$ \\
\hline 15. & Utilizing video projectors & 5 & $10.20 \%$ \\
\hline $16 . \quad$ Media literacy & 3 & $6.12 \%$ \\
\hline \hline
\end{tabular}

TABLE III: NORMALIZED CATEGORY WEIGHTS TO PARTICIPANTS’ NEEDS FOR NEW MEDIA EDUCATION TRAINING COURSES

\begin{tabular}{|c|c|c|}
\hline Category & Axis 1 & Axis2 \\
\hline 10. Utilizing overhead cameras (OHCs) & 0.773 & -1.164 \\
\hline $\begin{array}{l}\text { Utilizing interactive blackboards/ } \\
\text { whiteboards }\end{array}$ & 0.438 & -1.523 \\
\hline Utilizing tablet PCs & 0.367 & -1.588 \\
\hline 14. Digital presentation & 0.231 & -1.362 \\
\hline Designing ICT integrated lessons & 0.945 & 1.279 \\
\hline Capacity building for ICT integration & 0.763 & 1.220 \\
\hline 4. ICT integration in education & 0.676 & 0.779 \\
\hline 1. Utilizing digital textbooks & 0.563 & 0.457 \\
\hline 7. Utilizing ICT in specific subjects & 0.539 & 0.623 \\
\hline 8. Moral issues in education & -1.415 & 0.205 \\
\hline $\begin{array}{l}\text { F. Fostering positive attitudes towards joining } \\
\text { the information society }\end{array}$ & -1.450 & 0.144 \\
\hline 11. Information security & -1.748 & 0.355 \\
\hline 12. Utilizing social networking services (SNSs) & -1.817 & 0.082 \\
\hline 13. Issues in the information society & -1.887 & 0.237 \\
\hline
\end{tabular}

Responses were classified using Hayashi's quantification method type III. Item \# 15 (Utilizing video projectors) and \# 16 (Media literacy) were deleted from further analysis because few participants commented that they had these sort of needs, and if the items were included in the statistical analysis, they put too much category weight to all of the axes. Thus, 14 needs items were selected to be analyzed.

Table III shows the normalized category weights given to participants' needs for media education training courses. According to the tendency of the decrease of the eigenvalue (first axis: 0.6358 , second axis: 0.3051 , third axis: 0.1737 , fourth axis: 0.1324 ) and the cumulative proportion (first axis: 36.64 percent, second axis: 54.22 percent, third axis: 64.23 percent, forth axis: 71.86 percent), two axes were determined and interpreted.

Fig. 1 shows a two-dimensional scatter graph of the category scores of each item. Results of the statistical analysis indicate that the participants' needs for media education can be classified into three clusters.

The first cluster consists of four items: item \#2 (utilizing tablet PCs), \#3 (utilizing interactive blackboards/ whiteboards), \#10 (utilizing overhead cameras), and \#14 (digital presentation), that had relatively high category scores on the first correlation axis and low scores on the second axis. As all of the four items are related with knowledge and skills to utilize educational media in classroom lessons, the first cluster was given the name "utilizing media in education."

The second cluster includes five items: \#1 (utilizing digital textbooks), \#4 (ICT integration in education), \#5 (capacity building for ICT integration), \#6 (designing ICT integrated lessons), and \#7 (utilizing ICT in specific subjects), that had high category scores on both of the correlation axes. All of the five items are related with the designing and organizing ICT integrated lessons to improve classroom lesson, and therefore was named "ICT integration in education."

The third cluster also consists of five items: \#8 (moral issues in education), \#9 (fostering positives attitudes towards joining the information society), \#11 (information security), \#12 (utilizing social networking services), and \#13 (issues in the information society), that had low category scores on the first correlation axis. All of the five items are related with moral and/or security issues in education. Therefore, the third cluster was given the name "moral/security issues in education."

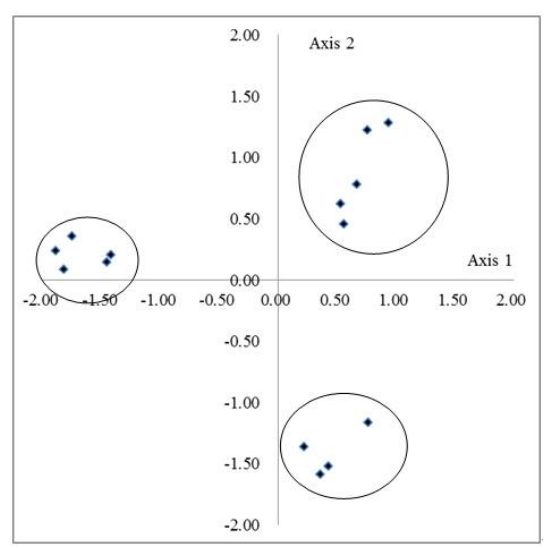

Fig. 1. Two-dimensional plot graph of participants' needs for media education training courses.

\section{Discussions}

The purpose of the study was to identify elementary and secondary teachers' needs for media education in-service 
teacher training courses. In order to gather teachers' needs, a four point Likert scale questionnaire was used to measure participants' needs for the current "curriculum standards" and a free-response style self-report questionnaire was used to identify the participants' needs for new media education teaching training courses.

Regarding the first research question "What are elementary and secondary school teachers' needs for the current "curriculum standards?," results of a questionnaire survey show that elementary and secondary teachers want to be trained on utilizing educational media, media literacy, utilizing media in education, utilizing presentation software in education, operating presentation software, utilizing hypermedia/multimedia in education, utilizing the Internet in education, operating the Internet, utilizing websites in education, utilizing educational software, moral issues and netiquette, copyright issues, protection of personal information, network security, rating and filtering information, protection from hazardous and harmful websites, managing and operating media in schools, while they recognize that they do not have to be trained on utilizing $16 \mathrm{~mm}$ movie projectors, utilizing slide projectors, utilizing overhead projectors, and producing and utilizing still images.

With regard to the second research question "What do elementary and secondary school teachers want to learn in media education in-service teacher training courses?," results of a questionnaire survey show that teachers desire to participate in training courses related with utilizing digital textbooks, utilizing tablet PCs, utilizing interactive blackboards/whiteboards, ICT integration in education, capacity building for ICT integration, designing ICT integrated lessons, utilizing ICT in specific subjects, and moral issues in education. It is interesting that although teacher consultants who are regional curriculum planners mentioned that they should train teachers how to utilize smartphones and mobile learning devices [9], elementary and secondary school teachers did not mention so.

Regarding the third research question "What is the structure of teachers' needs for media education training courses?," statistical analysis using Hayashi's quantification method type III revealed that the participants' needs for media education training courses can be classified into three groups, namely, "utilizing media in education," "ICT integration in education," and "moral/security issues in education."

\section{CONCLUSION}

The results of the study suggest that some contents of the current "curriculum standards" are needed to be revised, while there is still high need for most of the training topics. Specifically, there is relatively low need for training courses related with "old media" such as $16 \mathrm{~mm}$ movie projectors, overhead projectors, and still images. In contrast, teachers have high needs for training courses related with the theories of utilizing educational media, utilizing the Internet in education, moral and security issues in education, and digital presentation.

The results of this study also show that training courses related to designing and organizing ICT integrated lessons, utilizing new ICT media such as digital textbooks, tablet PCs and interactive blackboards/whiteboards should be added to the "curriculum standards." Among the 16 needs statements defined in this study, 7 statements were related with the training topics in the current "curriculum standards," while 9 were not. Thus, there is an urgent need to establish a system that enables perpetual revision or update of the "curriculum standards" so as to deal with the rapid change of the society and educational media.

Developing a useful teacher training curriculum with valid contents is essential for the effective management of teacher training courses. It is expected that the MEXT revises or updates the current "curriculum standards" in order to meet elementary and secondary teachers' needs.

\section{REFERENCES}

[1] A New Strategy in Information and Communications Technology (IT), Strategic Headquarters for the Promotion of an Advanced Information and Telecommunications Network Society, Tokyo, 2010.

[2] The Vision for ICT in Education -Toward the Creation of a Learning System and Schools Suitable for the 21st Century, Ministry of Education, Culture, Sports, Science and Technology, Tokyo, 2011.

[3] Countrywide Survey on the Situations of Informatization of Japanese Schools, Ministry of Education, Culture, Sports, Science and Technology, Tokyo, 2011.

[4] Declaration to be the World's Most Advanced IT Nation, Strategic Headquarters for the Promotion of an Advanced Information and Telecommunications Network Society, Tokyo, 2013.

[5] Audio-visual Education In-service Training Curriculum Standards, Social Education Bureau, Ministry of Education, Science, and Culture, Tokyo, 1973.

[6] Audiovisual/Media Education In-service Teacher Training Curriculum Standards, Ministry of Education, Culture, Sports, Science and Technology, Tokyo, 1992.

[7] Research Related to the Revision of the "Audiovisual/Media Education In-service Teacher Training Curriculum Standards”, Japan Audio-visual Education Association, Tokyo, 2006.

[8] H. Yoshida, "A formative evaluation of the model training plan for educational media specialists," Tokoha Gakuen University Research Review: Faculty of Education, vol. 30, pp. 439-453, March 2010.

[9] H. Yoshida, "A study of the emerging needs for in-service teacher training courses for ICT integration," in Proc. the 7th International Technology, Education, and Develop Conference, Valencia, Spain: IATED, 2013, pp. 3822-3827.

[10] Elementary School Course of Study, Ministry of Education, Culture, Sports, Science and Technology, Tokyo, 2008.

[11] Junior High School Course of Study, Ministry of Education, Culture, Sports, Science and Technology, Tokyo, 2008.

[12] Guideline on Informatization of Education, Ministry of Education, Culture, Sports, Science and Technology, Tokyo, 2010.

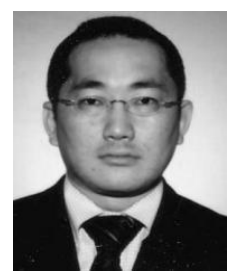

H. Yoshida was born in Nara, Japan in 1973. He received the MEd in educational technology from International Christian University, Japan in 2001. He is currently a professor of educational technology at Tokoha University in Shizuoka, Japan. His research interests include online learning, cooperative learning, hypermedia education, audio-visual education, and teacher education. 